\section{Spreading spondyloarthritis: are ILCs cytokine shuttles from base camp gut?}

\author{
Barbara Neerinckx, ${ }^{1,2}$ Dirk Elewaut, ${ }^{3,4}$ Rik J Lories ${ }^{1,2}$
}

A series of discoveries has transformed concepts of spondyloarthritis and proinflammatory cytokine interleukin-23 (IL-23) has taken centre stage. The IL-23 frenzy kicked off with the identification of single nucleotide polymorphisms in the IL-23 receptor (IL-23R) gene that are associated with ankylosing spondylitis $(\mathrm{AS})^{1}$ and also with related disorders such as psoriasis, psoriatic arthritis and Crohn's disease. The most striking and direct evidence comes from an in vivo IL-23 overexpression study in mice that phenocopies the human disease and its Janus-faced characteristics: joint inflammation and structural damage presenting as new bone formation. $^{2}$ Patient studies reported increased serum levels of IL-23 in $\mathrm{AS}^{3-5}$ and the presence of IL-23-positive cells was shown in facet joints of patients with AS. ${ }^{6}$ Direct clinical evidence comes from a prospective, open-label clinical trial with ustekinumab, an antibody binding to the shared p40 subunit of IL-23 and IL-12 ${ }^{7}$ and successful clinical trials targeting IL-17, one of the downstream cytokines associated with IL-23 signalling. ${ }^{8}$ Key to the hypothesis and evidence proposed in the mouse model is the presence of an IL-23 receptor-positive T-cell population in the enthesis of mice. As enthesitis is one of the main characteristics of AS and was proposed as the primary lesion, ${ }^{9}$ it is hard to ignore the potential key role of such cells. However, until now, these IL-23 receptor-positive cells have not yet been demonstrated in human samples.

Ciccia $e t a l^{10}$ report on the presence of a population of IL-23R-positive innate lymphoid cells (ILCs) in the gut, peripheral blood, synovial fluid and bone marrow of patients with AS. Numbers of such cells are increased as compared with different controls and their surface characteristics show similarities with the

\footnotetext{
${ }^{1}$ Laboratory of Tissue Homeostasis and Disease, Skeletal Biology and Engineering Research Center, KU Leuven, Leuven, Belgium; '2Division of Rheumatology, University Hospitals Leuven, Leuven, Belgium; ${ }^{3}$ Laboratory of Molecular Immunology and Inflammation, VIB Inflammation Research Center, Ghent University, Gent, Belgium; ${ }^{4}$ Division of Rheumatology, University of Ghent, Ghent, Belgium
}

Correspondence to Dr Rik J Lories, Skeletal Biology and Engineering Research Center, O\&N1, Box 813, Leuven B3000, Belgium; Rik.Lories@uz.kuleuven.be mouse cells identified earlier. However, these ILCs are a rare cell type whose significance in human disease is as yet uncertain. In two previous studies Ciccia et $a l^{11} 12$ showed increased IL-23 expression in the gut of patients with AS as compared with healthy controls. In AS synovium and peripheral blood cells, however, no differences in expression of IL-23 were found. ${ }^{13} 14$

They characterised these cells as

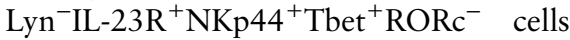
and the induced production of cytokines IL-17 and IL-22 led them to conclude that these are ILC3 cells. Unlike conventional ILC3 and IL-23R ${ }^{+}$entheseal T cells, these cells seemingly do not express RORc but do express the transcription factor Tbet which can, according to the authors, possibly be explained by a specific stage of differentiation of these cells. This finding makes them somewhat atypical, even for ILC3s. The reasons for these differences between 'conventional' characteristics of ILCs and the spondyloarthritis' associated cells are unclear and whether these changes precede onset of inflammation or are rather a secondary to already established inflammation remains to be determined. Further clarification of the exact nature of these cells clearly needs to be carried out. Hence, fine details in small subpopulations of cells may still represent a static, rather than dynamic, view on cell populations that are actively part of host defence or disease.

The expansion of these ILC3 cells in patients with AS with acute and chronic gut inflammation was significantly correlated with the disease activity as assessed by the Bath Ankylosing Spondylitis Disease Activity Index. In patients with AS without gut inflammation the upregulation of ILC3s was not detected. The authors reported an expansion of NKp44 + ILC3s in gut samples of patients with AS and in the peripheral blood, synovial fluid and the bone marrow of patients with AS. ILC3s are defined by their capacity to produce the interleukins IL-17 and IL-22, ${ }^{15}$ portrayed as critical cytokines in the pathogenesis of AS. In the study, gut ILC3 cells were demonstrated to produce IL-17 and IL-22 and a small percentage of cells expressed both cytokines. In the peripheral blood, the majority of ILC3s produced IL-22 and only a small subset of ILC3s produced IL-17 or the combination of IL-22 and IL-17. Among synovial fluid and bone marrow, mononuclear ILC3s produced exclusively IL-22. The reasons for these differential patterns according to localisation are unclear and could reflect tissue-imprinted cytokine patterns. These data suggest that ILCs could be an important supplier of IL-17 and IL-22 in AS, which is also one of the implicit conclusions of this study by Ciccia et al.

Insights into the role of IL-17 in spondyloarthritis are dynamically evolving with a shift from a focus on adaptive immune cells towards more innate immune populations. Indeed, IL-17 producing CD4+ cells, also known as Th17 cells, were shown to be elevated in HLA-B27/human $\beta 2 \mathrm{~m}$ transgenic rats ${ }^{16}$ and in the lymph nodes of an AS mouse model. ${ }^{17}$ Moreover, there are studies demonstrating an increased amount of IL-17-producing CD4 + cells in the blood of patients with AS as compared with controls ${ }^{18-21}$ although this observation is not consistent. $^{22-24}$ IL-17-producing cells were also found in the subchondral bone marrow cells of affected facet joints of patients with AS. ${ }^{6}$ Interestingly, the majority of these IL-17-positive cells were rather innate immune cells (CD15 + neutrophils and $\mathrm{MPO}+$ cells of the myeloid lineage) than CD4+ T cells. ${ }^{6}$ Obviously, the most convincing proof of principle that IL-17 plays a key role in spondyloarthritis is found in the clinical trials evaluating the effect of secukinumab, a monoclonal anti-IL-17A antibody that rapidly reduced clinical and biological signs of active AS. ${ }^{8}$

IL-22 has also earned its place in the spotlight as it has been associated with enthesitis/arthritis development in mice and with upregulation of genes potentially involved in the new bone formation process (such as Wnts and bone morphogenetic proteins). ${ }^{2}$ However, the role for IL-22 in AS and related disorders seems to be tissue dependent-as demonstrated in a study by Benham et $a l^{25}$ using the SKG mouse model. In this mouse model curdlan injection in SKG mice leads to IL-23-dependent axial and peripheral arthritis and ileitis. When IL-22 was neutralised by an IL-22 antibody, the mice developed a reduced severity of enthesitis but an exacerbation of ileitis. ${ }^{25}$ This finding highlights that the effects of interleukins in the pathogenesis of AS are not always straightforward but can vary from tissue to tissue and be influenced by tissue-dependent environmental factors. It is important to note that the current 
attention towards IL-23, IL-17 and IL-22 to some extent neglects the critical role of tumour necrosis factor (TNF) in this type of diseases. A TNF overexpression model mimics many features of the disease ${ }^{26}$ and TNF inhibition is currently the mainstay approach with high and sustained efficacy in SpA. Bringing together the different proinflammatory cytokines in one paradigm is therefore an interesting challenge.

Detailed histological analysis of the gut biopsies drives the authors to propose the hypothesis that IL-23 receptor-positive ILC3s differentiate in the gut and then migrate to extraintestinal sites where they produce IL-17 and IL-22. This hypothesis was formulated in part on the abundant expression of $\alpha 4 \beta 7$ integrin on ILC3s, a $\beta 7$ integrin with marked gut tropism, even though earlier work demonstrated its presence on synovial T cells in SpA synovium. ${ }^{27}$ Although this hypothesis touches the limits of careful observation in human samples without additional mechanistic experiments, the concept is certainly worth considering. Moreover, earlier this year Mackley et $a l^{28}$ provided the first in vivo evidence of ILC3 traffic starting from the gut in mice. The concept is also in line with old and new insights into the role of gut inflammation in spondyloarthritis. Five per cent to $10 \%$ of patients with AS suffer from clinically apparent inflammatory bowel disease (IBD) and even a much larger proportion of AS patients suffer from subclinical gut inflammation as already suggested in $1985 .^{29}$ In a recent study by Van Praet et $a l^{30} 46.2 \%$ of patients with AS showed microscopic gut inflammation of which $16.9 \%$ was acute and $29.2 \%$ was chronic inflammation. Patients with AS with chronic gut inflammation also have a higher degree of bone marrow oedema, as seen on MRI, further supporting a link between mucosal inflammation and progressive disease in AS. ${ }^{31}$ The gut is a barrier tissue continuously faced with the challenge of maintaining the symbiotic gut microbiome while avoiding local and systemic disease development by pathogenic microorganisms. New technologies can assess the gut microbiome in a systematic way. Different efforts are underway to link the microbiome with gut inflammation and joint disease in $\mathrm{SpA}$ and the results are eagerly awaited.

ILC3s are required for human immunity against extracellular bacteria and also play a role in chronic inflammation due to its proinflammatory characteristics. ${ }^{15}$ Keeping in mind that intestinal bacteria could play a role in the pathogenesis of AS, as described above, and that AS is a chronic inflammatory disease, the hypothesis that ILC3s are directly involved in the pathogenesis of AS sounds plausible. Of course, further research is necessary to, first, confirm the data and, second, further explore this hypothesis. If the hypothesis about the migration of IL-23 sensitised gut-resident ILC3s is correct, one of the key residual questions, for example, is how HLA-B27, the strongest risk factor for AS, fits in this story. Since HLA-B27 is a major histocompatibility complex class I molecule it will present endogenous antigens/peptides originating from the cytoplasm on the cell surface. These antigens/peptides include selfpeptides and can derive from viruses and bacteria. This peptide presentation could then possibly be the link to the gut microbiome. As the HLA-B27 gene is not linked to IBD, another possibility is that HLA-B27 does not play a role in disease induction in the gut, but only plays a role in inflammation at the joint level. Another question is how to explain joint inflammation in patients with AS without currently detectable gut inflammation. Notwithstanding the many additional questions, the paradigm proposed by Ciccia et al focusing on ILC3 cells as cytokine shuttle travelling from gut to blood, synovium and bone marrow in AS is an interesting new approach to the unravelling of spondyloarthritis' pathogenesis.

Contributors BN, DE and RJL wrote the paper together.

Funding Collaborative research of the authors on the topic is supported by grant G.0946.14 from the Flanders Research Foundation and by the DevRepair (P7/07) IAP-VII network (Belgian Federal Government).

Competing interests None declared.

Provenance and peer review Not commissioned; externally peer reviewed.

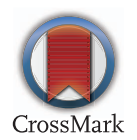

To cite Neerinckx B, Elewaut D, Lories RJ. Ann Rheum Dis 2015;74:1633-1635.

Received 8 June 2015

Revised 3 July 2015

Accepted 5 July 2015

Published Online First 21 July 2015

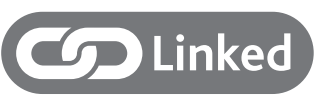
http://dx.doi.org/10.1136/annrheumdis-2014-
206323

Ann Rheum Dis 2015;74:1633-1635.

doi:10.1136/annrheumdis-2015-207735

\section{REFERENCES}

1 Burton PR, Clayton DG, Cardon LR, et al., Wellcome Trust Case Control Consortium; Australo-AngloAmerican Spondylitis Consortium (TASC). Association scan of 14,500 nonsynonymous SNPs in four diseases identifies autoimmunity variants. Nat Genet 2007;39:1329-37.

2 Sherlock JP, Joyce-Shaikh B, Turner SP, et al. IL-23 induces spondyloarthropathy by acting on ROR-gammat+ CD3+CD4-CD8- entheseal resident T cells. Nat Med 2012;18:1069-76.

3 Wang $X$, Lin Z, Wei Q, et al. Expression of IL-23 and IL-17 and effect of IL-23 on IL-17 production in ankylosing spondylitis. Rheumatol Int 2009:29:1343-7.

4 Mei Y, Pan F, Gao J, et al. Increased serum IL-17 and IL-23 in the patient with ankylosing spondylitis. Clin Rheumatol 2011;30:269-73.

5 Andersen T, Rasmussen TK, Hvid M, et al. Increased plasma levels of IL-21 and IL-23 in spondyloarthritis are not associated with clinical and MRI findings. Rheumatol Int 2012;32:387-93.

6 Appel H, Maier R, Bleil J, et al. In situ analysis of interleukin-23- and interleukin-12-positive cells in the spine of patients with ankylosing spondylitis. Arthritis Rheum 2013;65:1522-9.

7 Poddubnyy D, Hermann KG, Callhoff J, et al. Ustekinumab for the treatment of patients with active ankylosing spondylitis: results of a 28-week, prospective, open-label, proof-of-concept study (TOPAS). Ann Rheum Dis 2014;73:817-23.

8 Baeten D, Baraliakos X, Braun J, et al. Anti-interleukin-17A monoclonal antibody secukinumab in treatment of ankylosing spondylitis: a randomised, double-blind, placebo-controlled trial. Lancet 2013;382:1705-13.

9 Benjamin M, McGonagle D. The anatomical basis for disease localisation in seronegative spondyloarthropathy at entheses and related sites. J Anat 2001;199: 503-26

10 Ciccia F, Guggino G, Rizzo A, et al. Type 3 innate lymphoid cells producing IL-17 and IL-22 are expanded in the gut, in the peripheral blood, synovial fluid and bone marrow of patients with ankylosing spondylitis. Ann Rheum Dis 2015;74: 1739-47.

11 Ciccia F, Bombardieri M, Principato A, et al. Overexpression of interleukin-23, but not interleukin-17, as an immunologic signature of subclinical intestinal inflammation in ankylosing spondylitis. Arthritis Rheum 2009;60:955-65.

12 Ciccia F, Accardo-Palumbo A, Rizzo A, et al. Evidence that autophagy, but not the unfolded protein response, regulates the expression of IL-23 in the gut of patients with ankylosing spondylitis and subclinical gut inflammation. Ann Rheum Dis 2014;73:1566-74.

13 Neerinckx B, Carter S, Lories R. IL-23 expression and activation of autophagy in synovium and PBMCs of HLA-B27 positive patients with ankylosing spondylitis. Response to: 'Evidence that autophagy, but not the unfolded protein response, regulates the expression of IL-23 in the gut of patients with ankylosing spondylitis and subclinical gut inflammation' by Ciccia et al. Ann Rheum Dis 2014;73:e68.

14 Melis L, Vandooren B, Kruithof $E$, et al. Systemic levels of IL-23 are strongly associated with disease activity in rheumatoid arthritis but not spondyloarthritis. Ann Rheum Dis 2010;69: 618-23.

15 Artis $D$, Spits $H$. The biology of innate lymphoid cells. Nature 2015:517:293-301.

16 Glatigny S, Fert I, Blaton MA, et al. Proinflammatory Th17 cells are expanded and induced by dendritic cells in spondylarthritis-prone HLA-B27-transgenic rats. Arthritis Rheum 2012;64:110-20.

17 Abe Y, Ohtsuji M, Ohtsuji N, et al. Ankylosing enthesitis associated with up-regulated IFN-gamma 
and IL-17 production in (BXSB×NZB) F(1) male mice: a new mouse model. Mod Rheumatol 2009;19:316-22.

18 Jansen DT, Hameetman M, van Bergen J, et al. IL-17-producing CD4+ T cells are increased in early, active axial spondyloarthritis including patients without imaging abnormalities. Rheumatology (Oxford) 2015;54:728-35.

19 Shen H, Goodall JC, Hill Gaston JS. Frequency and phenotype of peripheral blood Th17 cells in ankylosing spondylitis and rheumatoid arthritis. Arthritis Rheum 2009;60:1647-56.

20 Jandus C, Bioley G, Rivals JP, et al. Increased numbers of circulating polyfunctional Th17 memory cells in patients with seronegative spondylarthritides. Arthritis Rheum 2008;58:2307-17.

21 Xueyi L, Lina C, Zhenbiao W, et al. Levels of circulating Th17 cells and regulatory T cells in ankylosing spondylitis patients with an inadequate response to anti-TNF-alpha therapy. J Clin Immunol 2013;33:151-61.

22 Kenna TJ, Davidson SI, Duan R, et al. Enrichment of circulating interleukin-17-secreting interleukin-23 receptor-positive gamma/delta T cells in patients with active ankylosing spondylitis. Arthritis Rheum 2012;64:1420-9.

23 Bautista-Caro MB, Arroyo-Villa I, Castillo-Gallego C, et al. Decreased Th17 and Th1 cells in the peripheral blood of patients with early non-radiographic axial spondyloarthritis: a marker of disease activity in HLA-B27(+) patients. Rheumatology (Oxford) 2013;52:352-62.

24 Appel H, Maier R, Wu P, et al. Analysis of IL-17(+) cells in facet joints of patients with spondyloarthritis suggests that the innate immune pathway might be of greater relevance than the Th17-mediated adaptive immune response. Arthritis Res Ther 2011;13:R95.

25 Benham H, Rehaume LM, Hasnain SZ, et al. Interleukin-23 mediates the intestinal response to microbial beta-1,3-glucan and the development of spondyloarthritis pathology in SKG mice. Arthritis Rheumatol 2014;66:1755-67.

26 Armaka M, Apostolaki M, Jacques $P$, et al. Mesenchymal cell targeting by TNF as a common pathogenic principle in chronic inflammatory joint and intestinal diseases. J Exp Med 2008;205:331-7.
27 Elewaut D, De Keyser F, Van Den Bosch F, et al. Enrichment of $T$ cells carrying beta7 integrins in inflamed synovial tissue from patients with early spondyloarthropathy, compared to rheumatoid arthritis. J Rheumatol 1998;25:1932-7.

28 Mackley EC, Houston S, Marriott $\mathrm{CL}$, et al. CCR7-dependent trafficking of RORgamma(+) ILCS creates a unique microenvironment within mucosal draining lymph nodes. Nat Commun 2015;6:5862.

29 Mielants H, Veys EM, Cuvelier C, et al. HLA-B27 related arthritis and bowel inflammation. Part 2. lleocolonoscopy and bowel histology in patients with HLA-B27 related arthritis. J Rheumatol 1985;12:294-8.

30 Van Praet L, Van den Bosch FE, Jacques P, et al. Microscopic gut inflammation in axial spondyloarthritis: a multiparametric predictive model. Ann Rheum Dis 2013;72:414-17.

31 Van Praet L, Jans L, Carron P, et al. Degree of bone marrow oedema in sacroiliac joints of patients with axial spondyloarthritis is linked to gut inflammation and male sex: results from the GIANT cohort. Ann Rheum Dis 2014;73:1186-9. 